\title{
LIBERALISMO POLÍTICO Y PROTECCIÓN DE LAS MINORÍAS
}

\author{
Armando Alvares GARCIA JÚNIOR*
}

*Profesor de derecho internacional público, derecho del comercio internacional y sistemas jurídicos no occidentales (grado en derecho), estructura económica mundial, negocios internacionales y dirección estratégica y política de la empresa - I (grado ADE), dirección estratégica y política de la empresa - II (curso de adaptación ADE) y negociación y marketing internacional (MBA ADE) en la Universidad Internacional de la Rioja, España. armando.alvares@unir.net

\section{Recebido em: 30/10/2013 - Aprovado em: 18/12/2013 - Disponibilizado em: 15/01/2014}

RESUMEN: Los grupos sociales minoritarios no son adecuadamente protegidos en el ámbito del liberalismo político porque sus principios básicos de neutralidad de la administración pública e igualdad legal no se compatibilizan con la atribución de derechos especiales a colectivos específicos.

PALABRAS CLAVE: Derechos humanos, liberalismo político, individualismo, multiculturalismo, universalidad.

\section{HUMAN RIGHTS AND POLITICAL LIBERALISM}

ABSTRACT: The social minority groups are not appropriately protected in the field of political liberalism because its basic principles of neutrality of public administration and legal equality are not compatible with the attribution of special rights to specific social groups.

KEYWORDS: Human rights, political liberalism, individualism, multiculturalism, universality.

\section{LAS MINORÍAS Y EL PENSAMIENTO POLÍTICO LIBERAL}

La protección de las minorías ha merecido una atención especial en los años noventa del siglo pasado, después del colapso de las utopías sociales de la modernidad.

La identidad, singularidad y sentido de pertenencia a un grupo específico no debería generar tanta admiración puesto que la humanidad está constituida por un evidente mosaico de naturaleza moral, religiosa, lingüística, social, cultural, étnica etc. Esa diversidad se observa dentro de cada estado, en mayor o menor proporción.

La homogeneidad no existe realmente, sino que deriva de una ficción que atendería a determinadas fuerzas políticas dominantes en un determinado momento histórico (Fink, 1981) ${ }^{1}$.

Existiría, así, en función de diferentes motivos, la construcción de determinadas formas de identidad cultural relativamente hegemónicas que en su proceso de edificación y consolidación nacional, pasan a relegar a un plan secundario, o mismo a ignorar, las peculiaridades identificativas de otros grupos sociales minoritarios.

Es verdad que, como afirma Kymlicka $(2010)^{2}$, la teoría liberal contemporánea ha discutido el tema del pluralismo cultural de las sociedades modernas valiéndose del constitucionalismo democrático.

\footnotetext{
${ }^{1}$ Fink, Hans. (1981). Social Philosophy. Londres: Routledge.

${ }^{2}$ Kymlicka, Will. (2010). Ciudadanía multicultural: Una teoría liberal de los derechos de las minorías. Barcelona: Ediciones Paidós.
} 
En este marco normativo, la asignación de derechos especiales encontraba como obstáculos tanto la dificultad de identificación de los grupos (incluyendo los criterios que debían ser adoptados) como la justificación jurídica en un contexto de limitación de capital económico y humano por parte del estado.

Comprender que grupos deben ser señalados como titulares de derechos especiales en un marco de igualdad jurídica es un tema delicado en virtud del posible riesgo de exclusión de otros grupos.

Si estas dos dificultades mencionadas ocurren en un marco estructural democrático, no es difícil imaginar los problemas advenidos de los abusos cometidos por las ideologías de signo totalitario. La persecución, la exclusión social, el genocidio, etc.

Evidentemente, no se puede ignorar que la multiculturalidad dimanante de los diversos grupos sociales afecta de una manera u otra la estructura de las sociedades modernas.

Los conflictos sociales quizá no desaparezcan con el reconocimiento oficial de las idiosincrasias propias de la identidad cultural, pero el apoyo oficial podría eventualmente representar un rol importante en el sentido de minimizarlos.

Es necesario verificar que el recorrido no es sencillo, puesto que el liberalismo político tradicionalmente se basa en la libertad individual, en la justicia social y en la idea de unidad nacional.
El colapso del pensamiento neoliberal, por un lado, y del comunismo totalitario, por otro, debe ser realmente superado para que en el proceso universalista de los derechos humanos, los intereses de las minorías sean adecuadamente tomados en cuenta por la sociedad internacional.

El paradojo de ese campo parece ser, como señala Kincaid $(2012)^{3}$, la necesidad de garantizar una convivencia armoniosa entre los derechos humanos (bajo la perspectiva individual del liberalismo) y los derechos especiales y colectivos de los grupos minoritarios.

De esa forma se podría teóricamente evitar disensiones mayores entre el universalismo asociado al estado democrático de derecho y la segmentación de los distintos grupos integrantes de la dimensión social del estado.

El liberalismo plantea, como muy bien observa Raws (1996) ${ }^{4}$, la discusión sobre la posibilidad de coexistencia en una misma sociedad - que se pretende estable y socialmente justa - de personas libres pero profundamente divididas por creencias, costumbres etc.

Esa necesidad identitaria y de pertenencia a un grupo minoritario puede armonizarse o no con los objetivos de consolidación social de toda la sociedad, constituida esta tanto por los grupos sociales mayoritarios

\footnotetext{
${ }^{3}$ Kincaid, Harold. (2012). Oxford Handbook of Philosophy of Social Science. Oxford: Oxford University Press.

${ }^{4}$ Raws, John. (1996). El liberalismo político. Barcelona: Crítica.
} 
como por los diversos grupos minoritarios.

En este proceso en que las minorías históricamente han sido víctimas del olvido o de la deliberada negligencia o agresión de otros grupos sociales (con la participación o no del gobierno de turno), las relaciones internacionales y el derecho internacional público son llamados a jugar un rol extremadamente importante aunque muchas veces puedan parecer insuficientes.

La verdad es que las políticas institucionales enfocadas a la protección de los grupos minoritarios, tanto en el ámbito interno como internacional, parecen padecer de un problema crónico asociado a su identificación.

Más que un contingente numérico, representan un aspecto del fenómeno social que, según Benton \& Craib $(2010)^{5}$, son adecuadamente apreciados mediante la observación de sus comportamientos sociales.

El trato discriminatorio e injusto que sus miembros vengan a recibir en el ámbito de una sociedad concreta hiere a la igualdad jurídica que debe existir entre todas las personas y que está proclamada en diversos instrumentos internacionales.

Es importante observar que ni todos los grupos minoritarios son depreciados. Muchas veces están ubicados en la cúspide social. Annoussamy $(2001)^{6}$ ilustra muy bien, en su exposición sobre

${ }^{5}$ Benton, Ted \& Craib, Ian. (2010). Philosophy of Social Science: The Philosophical Foundations of Social Thought. Londres: Palgrave.

${ }^{6}$ Annoussamy, David. (2001). Le droit indien en marche. París: Société de Législation Comparée. el derecho indio, que los poderosos Brahmanes siempre han sido el grupo minoritario en esa compleja sociedad. Los marginados, por el contrario, estarían representados por una inmensa mayoría constituida por campesinos y obreros de la casta Shudrá.

Así, el grupo minoritario que debe ser objeto de atención por el estado y la sociedad internacional, es aquél que se caracteriza por su posición de subordinación social relativamente al grupo dominante.

La conciencia de pertenencia a una comunidad o, para emplear otra expresión equiparable, la identidad colectiva compartida, puede distinguir un grupo de los demás pero jamás excluirlo de la protección legal.

$\mathrm{Si}$ esa protección no se realiza eficazmente por el propio estado, tendrá la sociedad internacional, con los instrumentos y medios apropiados, que actuar en el proceso de inclusión social.

El reconocimiento de un grupo minoritario está estrechamente relacionado con sus idiosincrasias. Este fragmento del mosaico social es endógenamente distinto de los demás grupos sociales.

\section{TITULARIDAD DE DERECHOS Y GRUPOS MINORITARIOS}

Cuando la sociedad internacional actúa con el objetivo de presionar un estado a reconocer la titularidad de derechos de los miembros de un grupo minoritario, no toma en cuenta si están dispersas o 
territorialmente concentradas (minorías etnoterritoriales).

Estos elementos son importantes para efectos de aplicación de las políticas sociales en el ámbito del territorio porque conllevan a dificultades operativas prácticas pero no son relevantes en lo que concierne al reconocimiento de derechos básicos.

Eso de modo algún significa que el derecho internacional público o las relaciones internacionales deban ser excluidos en aquellos casos en que los grupos minoritarios etnoterritoriales, en virtud de su mayor organización política, reivindiquen autogobiernos que impliquen en enfrentamientos abiertos $\mathrm{u}$ opresiones veladas desde los grupos socialmente mayoritarios. Estos temas, aunque relevantes, escapan del objetivo de este trabajo.

En lo que se refiere a los grupos étnicos esparcidos por el territorio, normalmente sus peticiones se restringen al reconocimiento público y oficial de su singularidad cultural.

En relación a ellos, la intervención de los miembros de la sociedad internacional (estados, organizaciones internacionales) es muchas veces necesaria porque los grupos minoritarios, como bien explica Glazer $(1997)^{7}$, tienden a sufrir un proceso de discriminación negativa por parte de los grupos sociales mayoritarios.

La defensa de esos grupos, sin embargo, se ve comprometida por el hecho de que

${ }^{7}$ Glazer, Nathan. (1997). We Are All Multiculturalists Now, Harvard. Harvard University Press. dentro del contexto liberal, el individualismo ha sido consagrado en detrimento del colectivismo.

La reducida atención deferida a las colectividades minoritarias responde a una tradición política occidental que históricamente, en estos últimos doscientos años, ha sido convocada a moldear las estructuras de la identidad nacional. El liberalismo político, y en este sentido estoy de acuerdo con Rex $(1996)^{8}$, suele apoyarse sobre la noción de neutralidad administrativa, previsibilidad y estabilidad de las libertades individuales.

Los regímenes democráticos occidentales de corte liberal han plasmado el individualismo en sus leyes fundamentales. Las normas jurídicas internacionales también consagran y afirman la titularidad de derechos $y$ obligaciones de la persona humana, no del colectivo en sí mismo.

Aunque el discurso liberal cumpla su función económica en lo que se refiere al laissez-faire, cuyos reflejos obviamente repercuten en el ámbito jurídico, lo que nos interesa exaltar es la coexistencia de la individualidad, por un lado, y la atribución de derechos especiales a determinados colectivos, por otro.

La protección internacional sobre la identidad étnica, cultural, religiosa y lingüística de los grupos minoritarios frente al principio de la igualdad de todos ante la ley ha sido conducida por la extinta Sociedad de Naciones

\footnotetext{
${ }^{8}$ Rex, John. (1996). Ethnic Minorities in the modern Nation State. Londres: MacMillan Press.
} 
relativamente a los grupos ubicados en Europa Central.

Sin embargo, como afirma Mccarthy $(1993)^{9}$, los resultados no han sido plenamente satisfactorios, pues bajo el pretexto de la protección, se buscaba legitimar actos de intervención de un estado sobre otro.

Por otro lado, la Organización de las Naciones Unidas parece enfatizar más la idea de prevención de la discriminación, lo que podría ser un reflejo de su empeño por reconstruir e integrar los países destrozados por la Segunda Guerra Mundial.

Con el debido respecto, no me parece de todo acertada la posición de Colwill $(1994)^{10}$ al considerar que la política de rechazo a la discriminación negativa, difundida a partir de esa época, no logra fomentar la conservación de la diversidad cultural.

El problema, creo, es que bajo el prisma operativo, en las legislaciones de corte liberal, las reclamaciones deben partir desde el individuo perteneciente a un grupo minoritario, no del propio grupo minoritario. El reconocimiento de la titularidad de derechos recae sobre el individuo, no sobre el grupo.

Además, el estado no debería agotar su actuación con la adopción de políticas preventivas o asistencialistas, puesto

\footnotetext{
${ }^{9}$ Mccarthy, Thomas. (1993). Universalismo multicultural. Variaciones sobre un tema ilustrado. Madrid:

Fundación BBV.

${ }^{10}$ Colwill, Jeremy. (1994). Los derechos humanos, la protección de las minorías y el agotamiento del Universalismo. Anales de la Cátedra Francisco Suárez, núm. 31, 209-218.
}

que para el mantenimiento y manifestación de sus peculiaridades culturales, es necesario que existan condiciones adecuadas.

\section{INDIVIDUALISMO, IGUALDAD JURÍDICA Y RECONOCIMIENTO DE NECESIDADES ESPECIALES DE LOS GRUPOS MINORITARIOS}

El tema aún no solucionado del individualismo y la igualdad jurídica, por un lado, y el reconocimiento de necesidades especiales por parte de los grupos minoritarios, por otro, colide con la noción profunda de que el titular de los derechos humanos es la persona individualmente considerada, independientemente del contexto social, económico y cultural en que se insiere. Todos tienen derecho a la aplicación igualitaria de la ley que, en una sociedad de corte liberal, busca plasmar y promover el carácter universalista de los derechos humanos.

Este es un aspecto particularmente interesante porque, según Honneth $(1997)^{11}$, posiblemente inspirado en Hegel, la conciencia de la identidad es justamente una consecuencia del contexto cultural.

Las manifestaciones culturales de los grupos minoritarios suelen exprimirse colectivamente $\mathrm{y}$ hasta mismo la expresión individual tiende a compatibilizarse con la expresión colectiva.

\footnotetext{
${ }^{11}$ Honneth, Axel. (1997). La lucha por el reconocimiento. Barcelona: Crítica.
} 
El Pacto de las Naciones Unidas sobre Derechos Civiles y Políticos, en su artículo 27, también consagra el individualismo:

"En los Estados en que existan minorías étnicas, religiosas o lingüísticas, no se negará a las personas que pertenezcan a dichas minorías el derecho que les corresponde, en común con los demás miembros de su grupo, a tener su propia vida cultural, a profesar $y$ practicar su propia religión y a emplear su propio idioma”.

Relativamente a la raza o al género, políticas públicas importantes en diferentes países buscan consagrar la tolerancia y la igualdad. La discriminación negativa que se realice en relación a esas personas no puede ser aceptada por el derecho. Las leyes fundamentales, además, son prodigas en proclamar la igualdad, uno de los baluartes del pensamiento liberal.

Glazer (1997) señala que una de las dificultades encontradas por el liberalismo político es la compulsión por reducir todo a la expresión individual. En este sentido, pugna que el sentido de pertenencia a un grupo social derivaría de una manifestación íntima, aunque cambiable, de la propia persona. El autor parte del principio de que el colectivo social no puede anular la autonomía individual.

En otras palabras, la persona, individualmente considerada, tendría el derecho de integrarse $o$ no en un determinado grupo. En la práctica la situación es un tanto distinta, puesto que tanto el grupo minoritario puede rechazar al individuo como, en relación a determinados aspectos, por ejemplo, la raza, esta elección no ser posible.

De cualquier modo, las necesidades de apoyo, reconocimiento y favorecimiento de condiciones para que se preserven y afloren son distintas entre los grupos en razón de factores diversos. El patrimonio cultural en una sociedad pluralista y multicultural no solamente necesita ser preservada pero también fomentada mediante políticas públicas.

Los actores internacionales, mediante tratados cooperativos, pueden llevar a cabo ese menester cuando la carencia de recursos o las propias condiciones sociales del estado en que el grupo minoritario se encuentre no permitan un impulso adecuado de eses objetivos.

\section{UNIVERSALIDAD DE LOS DERECHOS HUMANOS, INDIVIDUALISMO, MULTICULTURALISMO Y "POLÍTICA DE LA DIFERENCIA"}

Eso nos lleva al tema de la universalidad de los derechos humanos como la forma consustanciada de los principios morales universales del liberalismo de Habermas y Rawls $(1998)^{12}$.

El universalismo de los liberales es generalizado y abstracto, tanto se refiere al individuo particularmente considerado como a toda la humanidad. La necesidad de reconocimiento, apoyo y protección de un grupo social tiende a

\footnotetext{
${ }^{12}$ Habermas, Jürgen \& Rawls, John. (1998). Debate sobre el liberalismo político. Barcelona: Ediciones Paidós.
} 
recaer sobre el individuo. Es la persona, no el grupo, que tiene que valerse de los instrumentos jurídicos disponibles para pleitear junto a las instancias competentes la defensa de sus intereses.

En este sentido, el grupo perdería su importancia relativa ante el hombre, único ser capaz de trascender a todas las conformaciones y agrupaciones humanas. El derecho tiende a considerar el hombre despojado de sus grupos, por eso confiere a él, persona individual, la titularidad de derechos universales.

John Rawls (1996) ${ }^{13}$, al enfatizar la cooperación social y su distribución equitativa, busca reducir las desigualdades sociales $\sin$ herir la libertad y autonomía del individuo. El establecimiento de su conexión entre la filosofía moral y la filosofía política pretende concretamente evitar la reducción de la libertad y la igualdad entre las personas, elementos que considera esenciales para el desarrollo pleno de sus potencialidades.

La divergencia en que quiero centrarme, en este apartado, es la que existe entre el individualismo, bandera del liberalismo político, y el multiculturalismo, cuya teoría tradicionalmente se ha centrado en la dimensión particular, cultural e histórica de un grupo social determinado.

La concepción se aleja de la protección habitual que la norma jurídica hace de la titularidad colectiva de derechos. Los multiculturalistas, así, buscan enfatizar el vínculo del individuo con su grupo.

\footnotetext{
${ }^{13}$ Raws, John. (1996). El liberalismo político. Barcelona: Crítica.
}

La antropología no niega este aspecto, el derecho tampoco. El problema es que la protección jurídica suele recaer sobre el individuo integrante del grupo minoritario, no sobre el propio grupo como colectividad homogénea.

El tema de la homogeneidad, vista desde un prisma más amplio, genera dificultades importantes para la identificación de los grupos sociales. Las expresiones culturales están constituidas por una amalgama de elementos esencialmente heterogéneos (Khan, 1975) $)^{14}$. La denominada antropología cultural señala, por ejemplo, desde la religión y la lengua hasta la forma de organización social de los grupos humanos.

En el ámbito de las relaciones internacionales, bajo el prisma de la tríplice base cooperación, dialogo político y comercio, el tema de las minorías parece tener como trasfondo la necesidad de implementación de una política de reconocimiento activo de la diversidad cultural, tal como preconizado por Taylor (1994) ${ }^{15}$.

El individuo necesitaría del reconocimiento de los demás (reconocimiento intersubjetivo) para poder desarrollarse integralmente. Sin este reconocimiento, el individuo, o en nuestro caso, el grupo minoritario, sufriría una opresión indeseable. Existe, así, una relación muy estrecha entre, por un lado, la dignidad y el desarrollo individual y, por otro, el reconocimiento de las idiosincrasias del grupo.

\footnotetext{
${ }^{14}$ Kahn, J. S. (1975). El concepto de cultura: textos fundamentales. Barcelona: Anagrama. ${ }^{15}$ Taylor, Charles. (1994). La ética de la autenticidad. Barcelona: Paidós.
} 
La concesión de derechos "especiales" a ciertos grupos sociales minoritarios en el marco de una política pública activa y eficiente estaría enmarcada en la denominada "política de la diferencia" que el estado debe emprender con la ayuda cooperativa de los demás, si necesario.

La "política de la diferencia" necesitaría armonizarse con el principio liberal de la neutralidad de la esfera pública en lo que concierne a particularismos de grupos minoritarios. Tal como menciona Taylor, la neutralidad del estado, sin la aplicación activa de esa política, poco hace para reducir la opresión hacia esos grupos. Hasta el momento, no se ha solucionado satisfactoriamente el problema teórico entre la igualdad formal y los derechos especiales concedidos a grupos minoritarios, bajo la perspectiva de la neutralidad de la ley.

La opción, apoyada políticamente por el conjunto de la comunidad internacional, es el enfoque del incremento de oportunidades reales, pero para eso, el estado debe intervenir activamente para compensar el desequilibrio existente entre los diferentes grupos humanos. En otras palabras, se aplicaría el principio de la discriminación positiva.

En el estado democrático de derecho, la política de reconocimiento propiciadora de la igualdad de derechos y de la coexistencia entre diferentes subculturas no ha escapado de críticas. Habermas $(1991)^{16}$, por ejemplo, afirma que la idea de los derechos colectivos no es

\footnotetext{
${ }^{16}$ Habermas, Jürgen. (1991). La necesidad de revisión de la izquierda. Madrid: Tecnos.
}

necesaria, puesto que la igualdad puede ser lograda mediante el establecimiento de derechos individuales.

En este aspecto, Taylor (1994) ${ }^{17}$ parece discordar del postulado liberal invocado por Habermas, de que el estado democrático debe distinguir claramente entre política y cultura. El estado, para Habermas, debe preocuparse con la reproducción política pero no con la reproducción cultural de la sociedad.

\section{EL RECONOCIMIENTO DEL UNIVERSALISMO MULTICULTURAL}

Creo que la tendencia, en el ámbito de las relaciones internacionales, es el reconocimiento del universalismo multicultural, de la pluralidad de contextos culturales, tal como preconizaba Taylor (1993) ${ }^{18}$.

Sin embargo, si en las relaciones internacionales (incluyendo las plasmadas en tratados internacionales de comercio) los países occidentales buscan fomentar la democracia y el liberalismo político, el reconocimiento y la intervención del estado en favor de los grupos minoritarios escaparía del rol de neutralidad de la esfera pública, uno de los principios esenciales en cualquier estado democrático de derecho.

Salmeron $\quad(1998)^{19} \quad$ observa acertadamente que, bajo el prisma del

\footnotetext{
${ }^{17}$ Taylor, Charles. (1994). Argumentos filosóficos. Barcelona: Paidós.

${ }^{18}$ Taylor, Charles. (1993). El multiculturalismo y la política del reconocimiento. México: FCE.

${ }^{19}$ Salmerón, Fernando. (1998). Diversidad cultural y tolerancia. México: Paidós.
} 
liberalismo, la titularidad de los derechos individuales debería ser suficiente para la reivindicación de los intereses pertinentes pero, para que eso se concrete, el estado debe ofrecer las mismas condiciones de acceso a la justicia para cada persona, independientemente del grupo al cual pertenezca.

Para el acceso, según el autor, la persona necesitaría cumplir determinados requisitos formales contemplados previamente en la legislación y estar en el territorio estatal por un plazo razonable de tiempo. La apreciación de la "razonabilidad de su estancia”, así como su exacta configuración jurídica, recaería sobre las autoridades competentes del país. $\mathrm{La}$ fundamentación de ambas debe encontrar abrigo en la constitución del país.

En la norma constitucional reside el núcleo duro del orden democráticoliberal, justamente el que la sociedad internacional, con especial referencia a sus miembros más actuantes, como la Unión Europea, procura preservar y fomentar en el mundo.

El desarrollo cultural, tal como expresado por el Pacto Internacional de Derechos Civiles y Políticos (adoptado $\mathrm{y}$ abierto a la firma, ratificación y adhesión por la Asamblea General en su resolución 2200 A (XXI), de 16 de diciembre de 1966 y con entrada en vigor el 23 de marzo de 1976) en su artículo 27 , no puede ser considerado un derecho absoluto.

"En los Estados en que existan minorías étnicas, religiosas o lingüísticas, no se negará a las personas que pertenezcan a dichas minorías el derecho que les corresponde, en común con los demás miembros de su grupo, a tener su propia vida cultural, a profesar $\quad y$ practicar su propia religión y a emplear su propio idioma”.

Su previsión en el Pacto Internacional de Derechos Económicos, Sociales y Culturales (adoptado y abierto a la firma, ratificación y adhesión por la Asamblea General en su resolución 2200 A (XXI), de 16 de diciembre de 1966 y con entrada en vigor el 3 de enero de 1976, en su artículo 13, 1, parte final, tampoco puede ser considerado libre de cualquier limitación.

"1. Los Estados Partes en el presente Pacto reconocen el derecho de toda persona a la educación. Convienen en que la educación debe orientarse hacia el pleno desarrollo de la personalidad humana y del sentido de su dignidad, y debe fortalecer el respeto por los derechos humanos y las libertades fundamentales. Convienen asimismo en que la educación debe capacitar a todas las personas para participar efectivamente en una sociedad libre, favorecer la comprensión, la tolerancia y la amistad entre todas las naciones y entre todos los grupos raciales, étnicos o religiosos, $y$ promover las actividades de las Naciones Unidas en pro del mantenimiento de la paz".

La libertad de elección cultural está consagrada en el ámbito normativo interno e internacional, de modo que el derecho al desarrollo de la propia 
cultura no debe traducirse como la opresión de un grupo sobre los demás.

La norma constitucional suele garantizar el acceso igualitario a la justicia, como forma de nivelar a todos los individuos en la ciudadanía, algo que es fomentado también en las relaciones internacionales entre los estados.

El estado democrático puede vincular la identidad nacional a la cohesión social pero la sociedad seguirá siendo un gran mosaico cultural, aunque dominado por un grupo mayoritario o hegemónico. La interpretación universalista de los derechos humanos valora la titularidad individual de los derechos, sin concesiones especiales a los derechos colectivos de las minorías.

La colectividad puede, en la práctica social, funcionar como una fuerza limitadora de la libertad individual, como forma de garantizar la pureza e identidad del propio grupo minoritario. La otra faceta visible sería el propio derecho del grupo social minoritario a existir y preservar su identidad.

El genocidio o la aniquilación de grupos étnicos, religiosos etc. están prohibidos por el derecho internacional. La preservación de los grupos atendería a la multiculturalidad compatible con la visión del liberalismo político.

Siguiendo la misma línea de racionamiento, el integrismo fundamentalista, por ejemplo, no puede ser tolerado por el estado de derecho porque procuraría imponer a los demás grupos sociales sus propios hábitos culturales y códigos morales y de conducta (Habermas, 1999) ${ }^{20}$.

Sin embargo, no es necesario que se llegue a esta situación extrema. La opresión del grupo socialmente dominante (aunque no sea numéricamente mayoritario) sobre grupos minoritarios no puede ser contemplada por el derecho. Una norma jurídica que prevea la posibilidad de dominio de un grupo sobre otro no estaría acorde con la visión occidental del liberalismo político y tampoco con los principios actuantes en el seno de las relaciones internacionales.

Eso no significa que no existan dificultades reales para que un grupo minoritario se afirme socialmente. Simplemente no puede ser reputada como legítima cualquier restricción social en este sentido prevista en una norma jurídica. Caso exista, despertaría el rechazo de diversos actores internacionales.

Por otro lado, la protección conferida a las personas por el derecho - y asumida como legítima y adecuada en el ámbito de las relaciones internacionales occidentales - puede ser pleiteada a las instancias competentes en el caso de que el propio grupo minoritario oprima o cercee la libertad individual.

Kylimcka \& Wayne $(1997)^{21}$ señalan que debe existir: a) igualdad entre los grupos sociales, b) igualdad y libertad en el seno de cada uno de ellos relativamente a sus miembros

\footnotetext{
${ }^{20}$ Habermas, Jürgen. (1999). La inclusión del otro. Barcelona: Paidós.

${ }^{21}$ Kylimcka, Will \& Wayne, Norman. (1997). El retorno del ciudadano; La política, 3, 5-39.
} 
integrantes. En la práctica, sin embargo, la dinámica social tiende a valorar y fomentar determinadas relaciones $y$ grupos en detrimento de otros.

La identidad nacional pasa actualmente por la aceptación, como mínimo, de la existencia del multiculturalismo. La tolerancia y el desarrollo de políticas públicas activas e inclusivas de los grupos minoritarios no tienen por qué resquebrar el liberalismo político del estado democrático.

La integración social, sin embargo, debe ocurrir dentro de un marco jurídicoinstitucional que exalte determinados patrones como forma de establecer una uniformidad de valores que sirva de base para la estabilidad social.

La estabilidad ocurre, en este sentido, en detrimento de la exaltación y fomento de todos los grupos sociales existentes. Esos grupos, bajo esta perspectiva, necesitarían adecuarse a los patrones dominantes, consustanciados en los derechos fundamentales (igualdad, libertad, acceso a la justicia etc.) observados y cobrados por la sociedad internacional. La normalidad constitucional buscaría así evitar las turbulencias que potencialmente derivarían de la no existencia de patrones dominantes.

Tampoco sería de esperar que el derecho internacional o la política internacional apoyen la segregación de los diferentes grupos en guetos diversos. Esa postura sería contraproducente, porque es recomendable para la propia idea de nación que exista una conciencia política común, cuyos valores fundamentales serían pasibles de compartición con la convivencia.

Por esta razón Thiebaut $(1998)^{22}$ parece señalar que en la democracia liberal, la conexión existente entre diálogo intercultural y paz social necesita una política pública que fomente la participación igualitaria, o sea, sin obstaculizar el acceso a la ciudadanía plena a ningún grupo social. La piedra angular capaz de conciliar las idiosincrasias de cada grupo social y el universalismo sería el dialogo y el reconocimiento.

\section{REFERÊNCIAS BIBLIOGRÁFICAS}

Annoussamy, David. (2001). Le droit indien en marche. París: Société de Législation Comparée.

Benton, Ted \& Craib, Ian. (2010). Philosophy of Social Science: The Philosophical Foundations of Social Thought. Londres: Palgrave.

Colwill, Jeremy. (1994). Los derechos humanos, la protección de las minorías y el agotamiento del Universalismo. Anales de la Cátedra Francisco Suárez, núm. 31, 209-218.

Fink, Hans. (1981). Social Philosophy. Londres: Routledge.

Glazer, Nathan. (1997). We Are All Multiculturalists Now, Harvard. Harvard University Press.

Habermas, Jürgen \& Rawls, John. (1998). Debate sobre el liberalismo político. Barcelona: Ediciones Paidós.

\footnotetext{
${ }^{22}$ Thiebaut, Carlos. (1998). Vindicación del ciudadano. Barcelona: Paidós.
} 
Habermas, Jürgen. (1991). La necesidad de revisión de la izquierda. Madrid: Tecnos.

Habermas, Jürgen. (1999). La inclusión del otro. Barcelona: Paidós.

Honneth, Axel. (1997). La lucha por el reconocimiento. Barcelona: Crítica.

Kahn, J. S. (1975). El concepto de cultura: textos fundamentales.

Barcelona: Anagrama.

Kincaid, Harold. (2012). Oxford Handbook of Philosophy of Social Science. Oxford: Oxford University Press.

Kylimcka, Will \& Wayne, Norman. (1997). El retorno del ciudadano; $L a$ política, 3, 5-39.

Kymlicka, Will. (2010). Ciudadanía multicultural: Una teoría liberal de los derechos de las minorías. Barcelona: Ediciones Paidós.

Mccarthy, Thomas. (1993).

Universalismo multicultural. Variaciones sobre un tema ilustrado. Madrid: Fundación BBV.

Raws, John. (1996). El liberalismo político. Barcelona: Crítica.

Rex, John. (1996). Ethnic Minorities in the modern Nation State. Londres:

MacMillan Press.

Salmerón, Fernando. (1998). Diversidad cultural y tolerancia. México: Paidós.

Taylor, Charles. (1993). El

multiculturalismo y la política del reconocimiento. México: FCE.

Taylor, Charles. (1994). Argumentos filosóficos. Barcelona: Paidós.

Taylor, Charles. (1994). La ética de la autenticidad. Barcelona: Paidós. 